\title{
Toxicidade e capacidade de ligação de proteínas Cry1 a receptores intestinais de Helicoverpa armigera (Lepidoptera: Noctuidae)
}

\author{
Isis Sebastião(1), Ana Rita Nunes Lemes ${ }^{(1)}$, Camila Soares Figueiredo(1), Ricardo Antonio Polanczyk(2), \\ Janete Apparecida Desidério(1) e Manoel Victor Franco Lemos ${ }^{(1)}$
}

\begin{abstract}
(1)Universidade Estadual Paulista (Unesp), Departamento de Biologia Aplicada à Agropecuária, Rodovia Prof. Paulo Donato Castellane, Km 5 , CEP 14884-900 Jaboticabal, SP, Brasil.E-mail: isisebastiao@gmail.com, anarita_lemes@yahoo.com.br, camila_sfigueiredo@hotmail.com, janete@fcav.unesp.br, mvictor@fcav.unesp.br (2)Unesp, Departamento de Fitossanidade, CEP 14884-900 Jaboticabal, SP, Brasil. E-mail: rapolanc@fcav.unesp.br
\end{abstract}

Resumo - O objetivo deste trabalho foi avaliar a toxicidade e a capacidade de ligação das proteínas Cry1Aa, Cry1Ab, Cry1Ac e Cry1Ca, de Bacillus thuringiensis, a receptores intestinais de Helicoverpa armigera. Realizou-se análise de ligação das proteínas ativadas às vesículas de membrana da microvilosidade apical (VMMA) do intestino médio de $H$. armigera, além de ensaios de competição heteróloga para avaliar sua capacidade de ligação. Cry1Ac destacou-se como a proteína mais tóxica, seguida por Cry1Ab e Cry1Aa. A proteína Cry1Ca não foi tóxica às lagartas e, portanto, não foi possível determinar os seus parâmetros de toxicidade $\mathrm{CL}_{50}$ e $\mathrm{CL}_{90}$. As proteínas Cry1Aa, Cry1 Ab e Cry1Ac são capazes de se ligar a um mesmo receptor nas membranas intestinais, o que aumenta o risco do desenvolvimento de resistência cruzada. Portanto, a utilização conjunta dessas proteínas deve ser evitada.

Termos para indexação: Bacillus thuringiensis, manejo da resistência, manejo integrado de pragas, piramidação de genes, proteínas inseticidas, vesículas de membrana.

\section{Toxicity and binding capacity of Cry1 proteins to Helicoverpa armigera (Lepidoptera: Noctuidae) intestine receptors}

\begin{abstract}
The objective of this work was to evaluate the toxicity and the binding capacity of the Cry1Aa, $\mathrm{Cry} 1 \mathrm{Ab}$, Cry $1 \mathrm{Ac}$, and Cry $1 \mathrm{Ca}$ proteins, from Bacillus thuringiensis, to Helicoverpa armigera intestine receptors. Binding analysis of the activated proteins to the brush-border membrane vesicles (BBMV) in the midgut of $H$. armigera, besides heterologous competition assays to evaluate their binding capacity, was performed. Cry1 Ac stood out as the most toxic protein, followed by Cry1 Ab and Cry1 Aa. The Cry1Ca protein had no toxicity to the caterpillars and, therefore, it was not possible to evaluate its $\mathrm{LC}_{50}$ and $\mathrm{LC}_{90}$ toxicity parameters. The Cry1Aa, Cry1Ab, and Cry1Ac proteins are able to bind themselves to the same receptor in the midgut membrane, which increases the risk of developing cross-resistance. Therefore, the use of these proteins together should be avoided.
\end{abstract}

Index terms: Bacillus thuringiensis, resistance management, integrated pest management, gene pyramiding, insecticidal proteins, brush-border membrane vesicle.

\section{Introdução}

A introdução da praga exótica Helicoverpa armigera Hübner (Lepidoptera: Noctuidae) no Brasil fez com que medidas emergenciais fossem tomadas para o seu controle. Produtores de algodão no Sul da Bahia tiveram $80 \%$ de suas plantações destruídas por essa praga (Czepak et al., 2013), que, por ser altamente polífaga, também atacou outras culturas na região Nordeste, Centro-Oeste e Sul do País (Ávila et al., 2013; Specht et al., 2013). Na Austrália, na Índia e na China, H. armigera é considerada a praga de maior impacto econômico (Liao et al., 2002; Ibargutxi et al., 2008; Zhang et al., 2013), e a severidade do ataque está relacionada a seu hábito alimentar polífago, a sua boa capacidade de dispersão e a sua adaptação a diferentes ambientes (Tay et al., 2013; Leite et al., 2014).

Os impactos ambientais, bem como o desenvolvimento de resistência aos produtos químicos utilizados para o controle de lepidópteros-praga, têm aumentado o interesse por formas alternativas de controle, como o controle biológico com a bactéria Bacillus thuringiensis. Além disso, também é grande o interesse por transgênicos com genes codificadores 
de proteínas dessa bactéria, tóxicas a $H$. armigera, especialmente em países como China, Austrália e Índia (Liao et al., 2002; Zhang et al., 2013).

As chamadas proteínas Cry1 apresentam forma de cristais e são produzidas por B. thuringiensis em sua fase esporulante (Schnepf et al., 1998). Essas proteínas são amplamente utilizadas na agricultura, na forma de bioinseticidas ou em plantas transgênicas, e apresentam tamanho de aproximadamente $135 \mathrm{kDa}$, e $60 \mathrm{kDa}$ após clivagem, que é um processo fundamental para o desencadeamento de uma série de passos necessários para sua ativação. A ligação das proteínas aos receptores presentes nas microvilosidades do mesêntero larval do inseto (Vachon et al., 2012) é um passo essencial para conferir toxicidade a essas proteínas.

As proteínas das famílias Cryl (Cry1Aa, Cry1Ab e Cry1Ac) e Cry2 (Cry2Aa) apresentam bons graus de toxicidade a H. armigera (Li \& Bouwer, 2012, 2014). No entanto, dados da suscetibilidade de populações brasileiras da praga a proteínas Cry são praticamente inexistentes, o que torna estudos que objetivam estabelecer estratégias para seu controle imprescindíveis. Uma dessas estratégias visa ao desenvolvimento de plantas transgênicas piramidadas, para as quais se deve encontrar a melhor combinação possível entre as toxinas a serem utilizadas. Além disso, proteínas diferentes podem se ligar a um mesmo receptor intestinal, em diversas espécies de lepidópteros-praga (Karim et al., 2000; Hernández-Rodríguez et al., 2013). Assim, estudos de competição dessas proteínas pelos sítios de ação no intestino dos insetos são importantes para subsidiar estratégias de controle efetivas para a praga.

O objetivo deste trabalho foi avaliar a toxicidade e a capacidade de ligação das proteínas Cry1Aa, Cry1Ab, Cry1Ac e Cry1Ca, de Bacillus thuringiensis, a receptores intestinais de Helicoverpa armigera.

\section{Material e Métodos}

Foram avaliadas as proteínas Cry1Aa, Cry1Ab, CrylAc e Cry1Ca de B. thuringiensis. Para a produção dessas proteínas, seus respectivos genes foram clonados, separadamente, em linhagens recombinantes de Escherichia coli XL-1 Blue, que expressava apenas uma dessas proteínas. Os clones foram cedidos pelo Dr. Ruud A. de Maagd (Plant Research International, Wageningen, Holanda).

Os procedimentos para o cultivo dos clones e para obter a expressão de cada proteína foram realizados de acordo com protocolo descrito por Herrero et al. (2004). Utilizou-se o meio de cultivo "terrific broth" (TB) (12 g de triptona, $24 \mathrm{~g}$ de extrato de levedura, 2,31 $\mathrm{g}$ de $\mathrm{KH}_{2} \mathrm{PO}_{4}, 12,54 \mathrm{~g}$ de $\mathrm{K}_{2} \mathrm{HPO}_{4}, 4,0 \mathrm{~mL}$ de glicerol e q.p.s. $1.000 \mathrm{~mL}$ ), sólido, na primeira etapa de cultivo, e líquido, nas etapas posteriores. Já a etapa de crescimento dos clones foi feita sob incubação, a $28^{\circ} \mathrm{C}$, e agitação a $200 \mathrm{rpm}$, por 60 horas. As células cultivadas foram coletadas após centrifugação a 7.000 rpm por 8 min.

Para o rompimento celular, foi utilizado tampão $50 \mathrm{mmol} \mathrm{L}^{-1}$ de Tris/HCl, $\mathrm{pH} 8,0$, contendo 5,0 mmol L-1 de EDTA e $100 \mathrm{mmol} \mathrm{L}^{-1}$ de $\mathrm{NaCl}$ com lisozima $(800$ $\mu \mathrm{g} \mathrm{g}^{-1}$ de pellet). A suspensão foi tratada com desoxicolato de sódio (sal sódico do ácido desoxicolico)

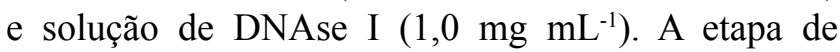
lavagem foi realizada, por três vezes, com $20 \mathrm{mmol} \mathrm{L}^{-1}$ de Tris/HCl, pH 7,5, contendo 1,0 $\mathrm{mol} \mathrm{L}^{-1}$ de $\mathrm{NaCl}$, e com $1 \%$ de Triton X-100. Em seguida, procedeu-se a três lavagens com solução salina tamponada contendo fosfato: $10 \mathrm{mmol} \mathrm{L}-1$ de $\mathrm{Na}_{2} \mathrm{HPO}_{4} / \mathrm{KH}_{2} \mathrm{PO}_{4}, \mathrm{pH} 7,4$, dissolvidos a $0,8 \%(\mathrm{p} / \mathrm{v}) \mathrm{NaCl}$. A solubilização das proteínas foi realizada em tampão $50 \mathrm{mmol} \mathrm{L}^{-1}$ de $\mathrm{NaHCO}_{3}, \mathrm{pH} 10,0$, contendo $100 \mathrm{mmol} \mathrm{L}^{-1}$ de $\mathrm{NaCl}$ e $10 \mathrm{mmol} \mathrm{L}^{-1}$ de DTT, com incubação por 3 horas, à temperatura ambiente, sob agitação horizontal. Para a coleta do sobrenadante com a proteína de interesse solubilizada, realizou-se centrifugação a $15.000 \mathrm{rpm}$, a $4^{\circ} \mathrm{C}$, por $15 \mathrm{~min}$. O sobrenadante coletado foi filtrado em membrana de poliestireno de $0,45 \mathrm{~mm}$.

A expressão das proteínas foi avaliada em gel de poliacrilamida com dodecil sulfato de sódio (SDS-Page) 12\% (Laemmli, 1970). As proteínas visualizadas no gel foram quantificadas pelo programa ImageQuant TL, versão 8.1 (GE Healthcare, Little Chalfont, Buckinghamshire, Reino Unido), por meio de uma curva de calibração da densitometria, com uso de albumina de soro bovino (BSA) como padrão de referência da concentração final.

Para a realização dos bioensaios de toxicidade, foram utilizadas lagartas neonatas de $H$. armigera de uma população oriunda de Luís Eduardo Magalhães, BA. A população foi coletada em campo, na cultura do feijoeiro, em 2013, e foi mantida em laboratório. As lagartas utilizadas estavam na décima primeira geração.

A análise de toxicidade foi realizada com todas as proteínas, exceto com a Cry1Ca, que não apresentou 
eficiência em ensaios preliminares. Nesses ensaios, foi utilizada uma concentração alta, de $1.000 \mathrm{ng} \mathrm{cm}^{-2}$, de cada toxina. Para a obtenção das concentrações letais médias $\left(\mathrm{CL}_{50} \mathrm{e} \mathrm{CL}_{90}\right)$, foram testadas seis concentrações, nos intervalos de: $39,06-1.250 \mathrm{ng} \mathrm{cm}^{-2}$ de Cry1Aa; 6,25-200 ng cm${ }^{-2}$ de Cry1 Ab; e 0,75-48 $\mathrm{ng} \mathrm{cm}^{-2}$ de Cry1Ac. O experimento foi realizado com a aplicação de $50 \mu \mathrm{L}$ do extrato proteico na superfície da dieta artificial semissólida (Liao et al., 2002), em placas de poliestireno com 128 poços (Cell Wells, Corning Inc., Corning, NY, EUA). Para cada concentração, foram utilizadas 50 lagartas neonatas, distribuídas em duas repetições de 25 lagartas cada uma. As lagartas foram acondicionadas individualmente em cada poço das placas de bioensaio. A testemunha foi composta pelo tampão de solubilização $\left(50 \mathrm{mmol} \mathrm{L}^{-1}\right.$ de $\mathrm{NaHCO}_{3}$, pH 10,0, com $100 \mathrm{mmol} \mathrm{L}^{-1} \mathrm{de} \mathrm{NaCl}+10 \mathrm{mmol} \mathrm{L}^{-1} \mathrm{de}$ DTT) das proteínas Cry.

Os tratamentos foram mantidos em ambiente com temperatura controlada $\left(26 \pm 2^{\circ} \mathrm{C}\right)$ e fotoperíodo de 14 horas de luz: 10 horas de escuro. A mortalidade foi avaliada aos 7 dias após a aplicação dos tratamentos, e a $\mathrm{CL}_{50}$ foi determinada por meio da análise de Probit (Finney, 1971), com auxílio do programa Polo-PC (LeOra Software, Petaluma, CA, EUA).

Lagartas de quarto ínstar de $H$. armigera foram dissecadas de acordo com Escriche et al. (1995), e as vesículas de membrana da microvilosidade apical do intestino (VMMA) foram preparadas pelo método de precipitação diferencial de magnésio (Wolfersberger et al., 1987). A concentração proteica nas VMMA, em cada preparação, foi determinada pelo método de Bradford (Bradford, 1976).

$\mathrm{O}$ processo de purificação das proteínas seguiu o princípio da troca catiônica, com uso de coluna HiTrap (GE Healthcare, Little Chalfont, Buckinghamshire, Reino Unido). Para a ativação das proteínas, utilizouse a tripsina pancreática bovina (Sigma-Aldrich, St. Louis, MO, EUA) a 10\%. As proteínas ativadas foram marcadas com biotina, com uso do kit ECL Protein Biotinylation Module (GE Healthcare, Little Chalfont, Buckinghamshire, Reino Unido), de acordo com as instruções do fabricante.

Para o ensaio de ligação, 100 ng de toxinas marcadas com biotina foram incubadas por 1 hora com as VMMA $(20 \mu \mathrm{g})$, em $100 \mu \mathrm{L}$ de tampão de ligação (tampão fosfato: $8,0 \mathrm{mmol} \mathrm{L}-1$ de $\mathrm{Na}_{2} \mathrm{HPO}_{4}, 2,0 \mathrm{mmol} \mathrm{L}^{-1}$ de $\mathrm{KH}_{2} \mathrm{PO}_{4}, 150 \mathrm{mmol} \mathrm{L}^{-1}$ de $\mathrm{NaCl}$ a pH 7,5 e $0,1 \%$ de
BSA). Os ensaios de competição heteróloga foram realizados como descrito por Fernandez et al. (2006). Para tanto, as incubações foram realizadas com as toxinas não biotiniladas, colocadas em excesso $(0,40,200$ e $1.000 \mathrm{x})$, em $100 \mu \mathrm{L}^{-1}$ de tampão de ligação (PBS $1 \mathrm{X}$ a pH 7,4, e Tween 20 a $0,1 \%$ v/v), à temperatura ambiente, durante $1 \mathrm{~h} 30 \mathrm{~min}$.

As VMMA foram lavadas duas vezes, com $500 \mu \mathrm{L}$ de tampão de ligação, e ressuspendidas em $10 \mu \mathrm{L}$ de água Milli-Q estéril e 5,0 $\mu \mathrm{L}$ de tampão de amostra de eletroforese (Laemmli, 1970). As amostras foram submetidas à eletroforese em gel SDS-PAGE 9\% e, em seguida, transferidas para uma membrana de nitrocelulose Hybond ECL, (GE Healthcare, Little Chalfont, Buckinghamshire, Reino Unido). As toxinas nas membranas foram detectadas com o anticorpo conjugado com estreptavidina-fosfatase alcalina (Roche, Basel, Suíça) em TBS $\left(0,05 \mathrm{mmol} \mathrm{L}^{-1}\right.$ de Tris-HCl, 0,15 mmol L-1 de NaCl, pH 7,5) + Tween 20 a $0,1 \%$ (v/v), diluição 1:2.000. A revelação foi feita com solução de BCIP/NBT Liquid Substrate System (Sigma-Aldrich, St. Louis, MO, EUA).

\section{Resultados e Discussão}

Do conjunto de proteínas avaliadas, a proteína Cry1Ac destacou-se como a de maior toxicidade para lagartas neonatas de $H$. armigera (Tabela 1 ). Os valores do intervalo de confiança da $\mathrm{CL}_{50}$ não se sobrepuseram; dessa forma, pode-se afirmar que as três proteínas apresentaram níveis de toxicidade estatisticamente diferentes. A proteína Cry1Ac foi 10 vezes mais tóxica que a proteína Cry1 $\mathrm{Ab}$ e aproximadamente 30 vezes

Tabela 1. Concentrações letais médias $\left(\mathrm{CL}_{50}\right.$ e $\left.\mathrm{CL}_{90}\right)-\mathrm{e}$ respectivos intervalos de confiança a $95 \%$ de probabilidade (entre parênteses) - das proteínas Cry1 avaliadas, para lagartas neonatas de Helicoverpa armigera $^{(1)}$.

\begin{tabular}{cccccc}
\hline Proteína & $\mathrm{CL}_{50}\left(\mathrm{ng} \mathrm{cm}^{-2}\right)$ & $\mathrm{CL}_{90}\left(\mathrm{ng} \mathrm{cm}^{-2}\right)$ & $\mathrm{b} \pm \mathrm{EP}$ & $\chi^{2}$ & $\mathrm{GL}$ \\
\hline Cry1Aa & 277,2 & $1.675,8$ & $1,64 \pm 0,15$ & $4,83^{*}$ & 5 \\
& $(222,1-344,9)$ & $(1.197,6-2.644,4)$ & & & \\
Cry1Ab & 87,5 & 787,3 & $1,34 \pm 0,17$ & $3,59^{*}$ & 5 \\
& $(65,6-127,2)$ & $(423,6-2.138,0)$ & & & \\
Cry1Ac & 8,8 & 72,9 & $1,39 \pm 0,18$ & $3,91^{*}$ & 5 \\
\hline
\end{tabular}

${ }^{(1)} \mathrm{b} \pm \mathrm{EP}$, coeficiente angular \pm erro-padrão da regressão entre as concentrações utilizadas das proteínas e a mortalidade da lagarta; e GL, graus de liberdade. ${ }^{*}$ Significativo a $5 \%$ de probabilidade pelo teste do qui-quadrado $\left(\chi^{2}\right)$. 
mais tóxica que a proteína Cry1Aa. $\mathrm{Na}$ avaliação da $\mathrm{CL}_{90}$, a proteína Cry1Ac também foi a mais tóxica, e os valores do intervalo de confiança das proteínas Cryl Aa e CrylAb se sobrepuseram, o que as classificou no mesmo nível de toxicidade.

Não foi realizada análise de toxicidade para a proteína $\mathrm{Cry} 1 \mathrm{Ca}$, que apresentou baixa toxicidade à concentração testada em ensaio prévio $\left(1.000 \mathrm{ng} \mathrm{cm}^{-2}\right)$. Insetos tolerantes a proteínas de $B$. thuringiensis, como as lagartas de Spodoptera cosmioides, Spodoptera eridania e Spodoptera frugiperda, tolerantes à proteína Cry1Ac, conseguem sobreviver mesmo submetidos a elevados níveis de concentração, como o utilizado no presente trabalho (Bernardi et al., 2014).

Resultados semelhantes de toxicidade foram relatados em populações do Sul da Espanha, por Avilla et al. (2005). Os autores observaram que a proteína Cry1Ac4 foi mais tóxica que a Cry2Aa1. Em populações da África do Sul, a proteína CrylAc aparece novamente como a mais tóxica, seguida das proteínas Cry2Aa, Cry1Ab e Cry1Aa (Li \& Bouwer, 2012).

Bird \& Akhurst (2007) relataram grande variação da $\mathrm{CL}_{50}$, para a proteína Cry1Ac, com valores de 23,3 a 107,6 $\mathrm{ng} \mathrm{cm}^{-2}$. Liao et al. (2002) reportaram valor de $\mathrm{CL}_{50}$ de $115 \mathrm{ng} \mathrm{cm}^{-2}$, para Cry1Ac, que é 13 vezes menos tóxico que os observados no presente trabalho. Essa variação pode estar relacionada à existência de populações resistentes na Austrália (Tabashnik et al., 2013).

Uma vez que ocorrem variações na suscetibilidade da praga a toxinas de $B$. thuringiensis, entre populações diferentes, uma mesma proteína pode apresentar maior ou menor letalidade nas diferentes populações estudadas.

As três proteínas Cry1Aa, Cry1Ab e Cry1Ac foram capazes de se ligar aos receptores presentes nas microvilosidades do intestino médio das lagartas (Figura 1). Lu et al. (2013) verificaram alta afinidade de ligação entre as VMMA de $H$. armigera e as proteínas Cry1 Ab e Cry1 Ac. Os autores observaram, no entanto, que o nível de saturação no sítio de ligação ocorre com o aumento da concentração das toxinas.

As proteínas avaliadas possivelmente se ligaram aos receptores do tipo aminopeptidases (APN), fosfatases alcalinas (ALP) e caderinas (CAD), descritos para diversos lepidópteros, inclusive $H$. armigera (Angeluci et al., 2008; Ning et al., 2010; Zhao et al., 2010).

A ligação das toxinas aos receptores é um dos determinantes para especificidade de ação das proteínas Cry, mas diferentes proteínas podem competir pelo mesmo receptor na membrana. Os resultados das competições heterólogas revelaram o compartilhamento do mesmo receptor entre as proteínas Cry1 Aa, Cry1 Ab e Cry1Ac (Figura 2). A proteína não marcada ligou-se aos receptores quando foi colocada em excesso, numa concentração de 1.000 x. Hernández-Rodríguez \& Juan Ferré (2005) também encontram o mesmo receptor para proteínas do grupo Cry1, em $H$. armigera. Os autores constataram que proteínas marcadas com biotina de Cry1Fa competiram com Cry1Ac e Cry1Ja pelo mesmo sítio ativo.

O compartilhamento do mesmo receptor também foi relatado para outros lepidópteros-praga: Ostrinia nubilalis, S. frugiperda, Plutella xylostella, Diatraea saccharalis, Heliothis virescens, Helicoverpa zea e Pectinophora gossypiella (Ballester et al., 1999; Karim et al., 2000; Jurat-Fuentes \& Adang, 2001; Hernández-Rodríguez et al., 2013; Davolos et al., 2015). Esse compartilhamento pode estar relacionado a similaridades na sequência de aminoácidos, nas regiões II e III das proteínas Cry1Aa, Cry1Ab e Cry1Ac, visto que são regiões fundamentais e específicas para o modo de ligação dessas proteínas (Schnepf et al., 1998; Pardo-López et al., 2013).

Ao se considerar a ausência de resultados de suscetibilidade de $H$. armigera a proteínas de

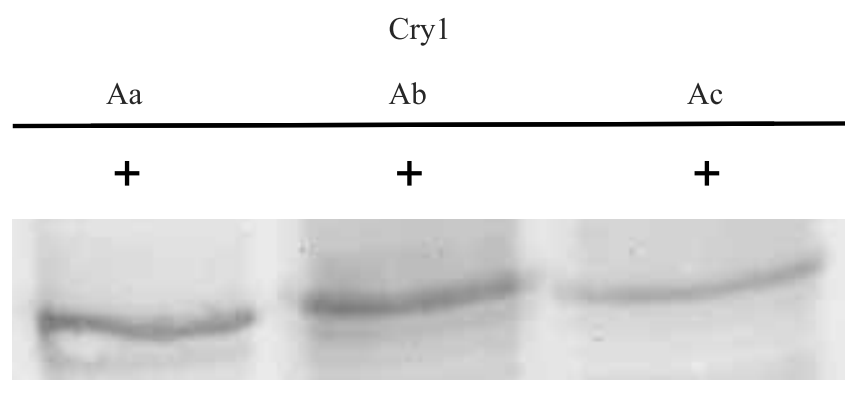

Figura 1. Capacidade de ligação das proteínas CrylAa, Cry1Ab e Cry1Ac, marcadas com biotina, aos receptores de vesículas de membrana da microvilosidade apical do intestino médio de lagartas de Helicoverpa armigera. $\mathrm{O}$ sinal positivo indica a união das proteínas aos receptores. 


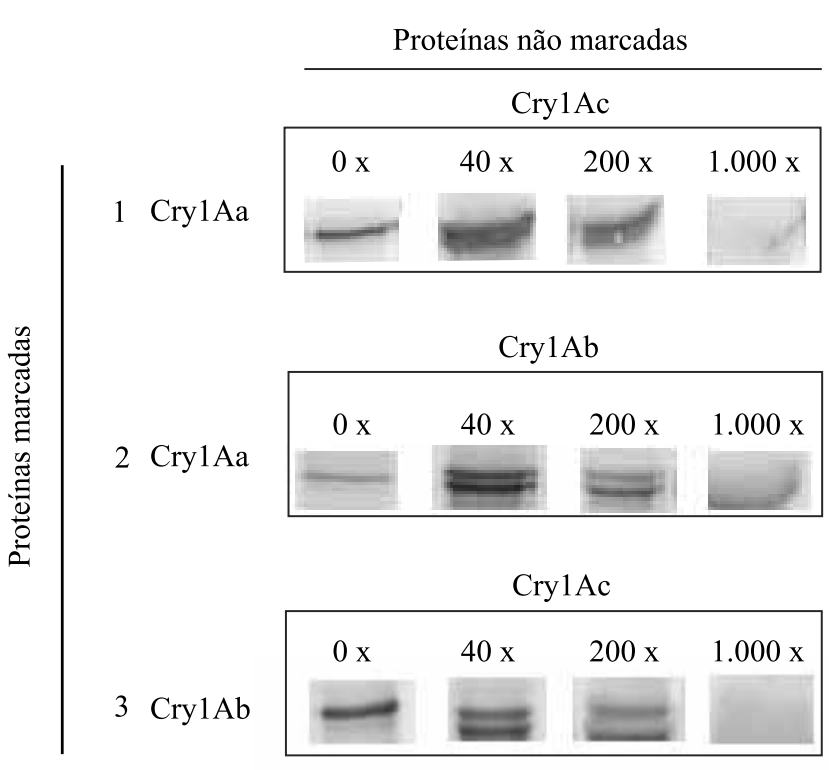

Figura 2. Resultados do ensaio de competição heteróloga - por receptores intestinais de lagartas de Helicoverpa armigera - das proteínas Cry1 avaliadas. Linha 1, Cry1Aa marcada e Cry1Ac não marcada; linha 2, Cry1Aa marcada e CrylAb não marcada; e linha 3, CrylAb marcada e CrylAc não marcada. Os valores 0 x, 40 x, 200 x e 1.000 x representam a quantidade de vezes que a proteína não marcada foi colocada em excesso.

B. thuringiensis no Brasil, o presente trabalho apresenta uma linha básica de suscetibilidade dessa praga a proteínas Cry1. Além disso, o relato da competição das proteínas Cry1Aa, Cry1Ab e Cry1Ac por um mesmo sítio tem implicações importantes na construção de plantas piramidadas, em que proteínas Cryl devem ser preferencialmente combinadas com outras classes de proteínas, como a Cry2.

\section{Conclusões}

1. A proteína Cry1Ac é a mais tóxica para Helicoverpa armigera, seguida das proteínas Cry1Ab e Cry1Aa, enquanto a proteína Cry1Ca não apresenta toxicidade à praga.

2. As proteínas Cry1Aa, Cry1Ab e Cry1Ac são capazes de se ligar aos receptores da membrana do intestino médio de $H$. armigera, mas compartilham entre si o mesmo receptor, o que indica que a utilização conjunta dessas proteínas deve ser evitada.

\section{Agradecimentos}

À Coordenação de Aperfeiçoamento de Pessoal de Nível Superior (Capes), pelo apoio financeiro; ao Professor Dr. Ruud de Maagd, do Plant Research International, por ceder os clones das proteínas Cry1; e ao Laboratório de Resistência de Artrópodes a Táticas de Controle, do Departamento de Entomologia e Acarologia, da Escola Superior de Agricultura Luiz de Queiroz, por ceder os insetos utilizados no presente trabalho.

\section{Referências}

ANGELUCCI， C.; BARRETT-WILT, G.A.; HUNT, D.F.; AKHURST, R.J.; EAST, P.D.; GORDON, K.H.J.; CAMPBELL, P.M. Diversity of aminopeptidases, derived from four lepidopteran gene duplications, and polycalins expressed in the midgut of Helicoverpa armigera: identification of proteins binding the $\delta$-endotoxin, Cry1Ac of Bacillus thuringiensis. Insect Biochemistry and Molecular Biology, v.38, p.685-696, 2008. DOI: 10.1016/j.ibmb.2008.03.010.

ÁVILA, C.J.; VIVAN, L.M.; TOMQUELSKI, G.V. Ocorrência, aspectos biológicos, danos e estratégias de manejo de Helicoverpa armigera (Hübner) (Lepidoptera: Noctuidae) nos sistemas de produção agrícolas. Dourados: Embrapa Agropecuária Oeste, 2013. 12p. (Embrapa Agropecuária Oeste. Circular técnica, 23).

AVILLA, C.; VARGAS-OSUNA, E.; GONZÁLEZ-CABRERA, J.; FERRÉ, J.; GONZÁLEZ-ZAMORA, J.E. Toxicity of several $\delta$-endotoxins of Bacillus thuringiensis against Helicoverpa armigera (Lepidoptera: Noctuidae) from Spain. Journal of Invertebrate Pathology, v.90, p.51-54, 2005. DOI: 10.1016/j. jip.2005.04.003.

BALLESTER, V.; GRANERO, F.; TABASHNIK, B.E.; MALVAR, T.; FERRÉ, J. Integrative model for binding of Bacillus thuringiensis toxins in susceptible and resistant larvae of the diamondback moth (Plutella xylostella). Applied and Environmental Microbiology, v.65, p.1413-1419, 1999.

BERNARDI, O.; SORGATTO, R.J.; BARBOSA, A.D.; DOMINGUES, F.A.; DOURADO, P.M.; CARVALHO, R.A.; MARTINELLI, S.; HEAD, G.P.; OMOTO, C. Low susceptibility of Spodoptera cosmioides, Spodoptera eridania and Spodoptera frugiperda (Lepidoptera: Noctuidae) to genetically-modified soybean expressing Cry1Ac protein. Crop Protection, v.58, p.33-40, 2014. DOI: 10.1016/j.cropro.2014.01.001.

BIRD, L.J.; AKHURST, R.J. Variation in susceptibility of Helicoverpa armigera (Hübner) and Helicoverpa punctigera (Wallengren) (Lepidoptera: Noctuidae) in Australia to two Bacillus thuringiensis toxins. Journal of Invertebrate Pathology, v.94, p.84-94, 2007. DOI: 10.1016/j.jip.2006.08.005.

BRADFORD, M.M. A rapid and sensitive method for the quantitation of microgram quantities of protein utilizing the 
principle of protein-dye binding. Analytical Biochemistry, v.72, p.248-254, 1976. DOI: 10.1016/0003-2697(76)90527-3.

CZEPAK, C.; ALBERNAZ, K.C.; VIVAN, L.M.; GUIMARÃES, H.O.; CARVALHAIS, T. Primeiro registro de ocorrência de Helicoverpa armigera (Hübner) (Lepidoptera: Noctuidae) no Brasil. Pesquisa Agropecuária Tropical, v.43, p.110-113, 2013. DOI: $10.1590 /$ S1983-40632013000100015.

DAVOLOS, C.C.; HERNÁNDEZ-MARTINEZ, P.; CRIALESI-LEGORI, P.C.B.; DESIDÉRIO， J.A.; FERRÉ, J.; ESCRICHE, B.; LEMOS, M.V.F. Binding analysis of Bacillus thuringiensis Cry1 proteins in the sugarcane borer, Diatraea saccharalis (Lepidoptera: Crambidae). Journal of Invertebrate Pathology, v.127, p.32-34, 2015. DOI: 10.1016/j.jip.2015.01.013.

ESCRICHE, B.; SILVA, F.J.; FERRÉ, J. Testing suitability of brush border membrane vesicles prepared from whole larvae from small insects for binding studies with Bacillus thuringiensis Cry1A(b) crystal protein. Journal of Invertebrate Pathology, v.65, p.318-320, 1995. DOI: 10.1006/jipa.1995.1051.

FERNANDEZ, L.E.; AIMANOVA, K.G.; GILL, S.S.; BRAVO, A.; SOBERÓN, M. A GPI anchored alkaline phosphatases is a functional midgut receptor of Cry11Aa toxin in Aedes aegypti larvae. Biochemical Journal, v.394, p.77-84, 2006. DOI: 10.1042/ BJ20051517.

FINNEY, D.J. Probit analysis: a statistical treatment of the sigmoid response curve. $3^{\text {rd }}$ ed. New York: Cambridge University, 1971. 333p.

HERNÁNDEZ-RODRÍGUEZ, C.S.; HERNÁNDEZ-MARTÍNEZ, P.; VAN RIE, J.; ESCRICHE, B.; FERRÉ, J. Shared midgut binding sites for Cry1A.105, Cry1Aa, Cry1Ab, Cry1Ac and Cry1Fa proteins from Bacillus thuringiensis in two important corn pests, Ostrinia nubilalis and Spodoptera frugiperda. PLoS ONE, v.8, article e68164, 2013. DOI: 10.1371/journal.pone.0068164.

HERNÁNDEZ-RODRÍGUEZ, C.S.; JUAN FERRÉ, J. Common receptor for Bacillus thuringiensis toxins Cry1Ac, Cry1Fa, and Cry1Ja in Helicoverpa armigera, Helicoverpa zea, and Spodoptera exigua. Applied and Environmental Microbiology, v.71, p.5627-5629, 2005. DOI: 10.1128/AEM.71.9.5627-5629.2005.

HERRERO, S.; GONZÁLEZ-CABRERA， J.; FERRÉ, J.; BAKKER, P.L.; MAAGD, R.A. de. Mutations in the Bacillus thuringiensis Cry1Ca toxin demonstrate the role of domains II and III in specificity towards Spodoptera exigua larvae. Biochemical Journal, v.384, p.507-513, 2004. DOI: 10.1042/BJ20041094.

IBARGUTXI, M.A.; MUÑOZ, D.; ESCUDERO, I.R. de; CABALLERO, P. Interactions between Cry1Ac, Cry2Ab, and Cry1Fa Bacillus thuringiensis toxins in the cotton pests Helicoverpa armigera (Hübner) and Earias insulana (Boisduval). Biological Control, v.47, p.89-96, 2008. DOI: 10.1016/j. biocontrol.2008.07.003.

JURAT-FUENTES, J.L.; ADANG, M.J. Importance of Cry1 $\delta$-Endotoxin domain II loops for binding specificity in Heliothis virescens (L.). Applied and Environmental Microbiology, v.67, p.323-329, 2001. DOI: 10.1128/AEM.67.1.323-329.2001.

KARIM, S.; RIAZUDDIN, S.; GOULD, F.; DEAN, D.H. Determination of receptor binding properties of Bacillus thuringiensis $\delta$-endotoxins to cotton bollworm (Helicoverpa zea) and pink bollworm (Pectinophora gossypiella) midgut brush border membrane vesicles. Pesticide Biochemistry and Physiology, v.67, p.198-216, 2000. DOI: 10.1006/pest.2000.2491.

LAEMMLI, U.K. Cleavage of structural proteins during the assembly of the head of bacteriophage T4. Nature, v.227, p.680-685, 1970. DOI: 10.1038/227680a0.

LEITE, N.A.; ALVES-PEREIRA, A.; CORRÊA, A.S.; ZUCCHI, M.I.; OMOTO, C. Demographics and genetic variability of the new world bollworm (Helicoverpa zea) and the old world bollworm (Helicoverpa armigera) in Brazil. PLoS ONE, v.9, article e113286, 2014. DOI: 10.1371/journal.pone.0113286.

LI, H.; BOUWER, G. Evaluation of the synergistic activities of Bacillus thuringiensis Cry proteins against Helicoverpa armigera (Lepidoptera: Noctuidae). Journal of Invertebrate Pathology, v.121, p.7-13, 2014. DOI: 10.1016/j.jip.2014.06.005.

LI, H.; BOUWER, G. Toxicity of Bacillus thuringiensis Cry proteins to Helicoverpa armigera (Lepidoptera: Noctuidae) in South Africa. Journal of Invertebrate Pathology, v.109, p.110-116, 2012. DOI: 10.1016/j.jip.2011.10.005.

LIAO, C.; HECKEL, D.G.; AKHURST, R. Toxicity of Bacillus thuringiensis insecticidal proteins for Helicoverpa armigera and Helicoverpa punctigera (Lepidoptera: Noctuidae), major pests of cotton. Journal of Invertebrate Pathology, v.80, p.55-63, 2002. DOI: 10.1016/S0022-2011(02)00035-6.

LU, Q.; CAO, G.-C.; ZHANG, L.-L.; LIANG, G.-M.; GAO, X.-W.; ZHANG, Y.-J.; GUO, Y.-Y. The binding characterization of Cry insecticidal proteins to the brush border membrane vesicles of Helicoverpa armigera, Spodoptera exigua, Spodoptera litura and Agrotis ipsilon. Journal of Integrative Agriculture, v.12, p.1598-1605, 2013. DOI: 10.1016/S2095-3119(13)60427-X.

NING, C.; WU, K.; LIU, C.; GAO, Y.; JURAT-FUENTES, J.L.; GAO, X. Characterization of a Cry1Ac toxin-binding alkaline phosphatase in the midgut from Helicoverpa armigera (Hübner) larvae. Journal of Insect Physiology, v.56, p.666-672, 2010. DOI: 10.1016/j.jinsphys.2010.02.003.

PARDO-LÓPEZ, L.; SOBERÓN, M.; BRAVO, A. Bacillus thuringiensis insecticidal three-domain Cry toxins: mode of action, insect resistance and consequences for crop protection. FEMS Microbiology Review, v.37, p.3-22, 2013. DOI: 10.1111/j.15746976.2012.00341.x.

SCHNEPF, E.; CRICKMORE, N.; VAN RIE, J.; LERECLUS, D.; BAUM, J.; FEITELSON, J.; ZEIGLER, D.R.; DEAN, D.H. Bacillus thuringiensis and its pesticidal crystal proteins. Microbiology and Molecular Biology Reviews, v.62, p.775-806, 1998.

SPECHT, A.; SOSA-GÓMEZ, D.R.; PAULA-MORAES, S.V. de; YANO, S.A.C. Identificação morfológica e molecular de Helicoverpa armigera (Lepidoptera: Noctuidae) e ampliação de seu registro de ocorrência no Brasil. Pesquisa Agropecuária Brasileira, v.48, p.689-692, 2013. DOI: 10.1590/ S0100-204X2013000600015.

TABASHNIK, B.E.; BRÉVAULT, T.; CARRIÈRE, Y. Insect resistance to Bt crops: lessons from the first billion acres. Nature Biotechnology, v.31, p.510-521, 2013. DOI: 10.1038/nbt.2597. 
TAY, W.T.; SORIA, M.F.; WALSH, T.; THOMAZONI, D.; SILVIE, P.; BEHERE, G.T.; ANDERSON, C.; DOWNES, S. A brave new world for an old world pest: Helicoverpa armigera (Lepidoptera: Noctuidae) in Brazil. PLoS One, v.8, article e80134, 2013. DOI: 10.1371/journal.pone.0080134.

VACHON, V.; LAPRADE, R.; SCHWARTZ, J.-L. Current models of the mode of action of Bacillus thuringiensis insecticidal crystal proteins: a critical review. Journal of Invertebrate Pathology, v.111, p.1-12, 2012. DOI: 10.1016/j.jip.2012.05.001.

WOLFERSBERGER, M.; LUETHY, P.; MAURER, A.; PARENTI, P.; SACCHI, F.V.; GIORDANA, B.; HANOZET, M. Preparation and partial characterization of amino acid transporting brush border membrane vesicles from the larval midgut of the cabbage butterfly (Pieris brassicae). Comparative Biochemistry and Physiology Part A: Physiology, v.86, p.301-308, 1987. DOI: 10.1016/0300-9629(87)90334-3.

ZHANG, H.; TANG, M.; YANG, F.; YANG, Y.; WU, Y. DNA-based screening for an intracellular cadherin mutation conferring non-recessive Cry1Ac resistance in field populations of Helicoverpa armigera. Pesticide Biochemistry and Physiology, v.107, p.148-152, 2013. DOI: 10.1016/j.pestbp.2013.06.007.

ZHAO, J.; JIN, L.; YANG, Y.; WU, Y. Diverse cadherin mutations conferring resistance to Bacillus thuringiensis toxin Cry1Ac in Helicoverpa armigera. Insect Biochemistry and Molecular Biology, v.40, p.113-118, 2010. DOI: 10.1016/j. ibmb.2010.01.001.

Recebido em 25 de março de 2015 e aprovado em 31 de agosto de 2015 